\title{
THE ASTROPHYSICAL OBSERVATORY OF THE CALIFORNIA INSTITUTE OF TECHNOLOGY
}

GEORGE E. HALE

Reprinted for private circulation from

The Astrophysical Journal, Vol. 82, No. 2, September 1935

PRINTED IN THE U.S.A. 


\title{
THE ASTROPHYSICAL OBSERVATORY OF THE CALIFORNIA INSTITUTE OF TECHNOLOGY
}

\author{
By GEORGE E. HALE
}

\begin{abstract}
Introduction.-Gift by Rockefeller Trustees to California Institute of Technology of fund to establish an Astrophysical Observatory with 200-inch telescope; co-operation with Carnegie Institution of Washington.

The 200-inch telescope--Selection of equatorial reflector; mirror disks; experiments with fused silica; adoption of new type of Pyrex glass, of low-temperature expansion; successful production of 60-inch, I 20 -inch, and 200-inch Pyrex disks; development of aluminum mirror surfaces; types of equatorial mountings; yoke type selected.

Site.-Choice between Northern and Southern hemispheres; mountain site near California Institute and Mount Wilson Observatory necessary for most effective work; five years' study of meteorological, topographical, and astronomical conditions at several favorable sites; other requirements; final selection to be made soon.

Astrophysical laboratory.-Purposes of laboratory; site in Pasadena on California Institute campus; brief description.

Instrument shop.-Purpose; site; equipment.

Optical shop.-Requirements; site; equipment.

Auxiliary instruments.- Attachments of 200 -inch telescope; Ross correcting lens; tests with Mount Wilson telescopes; Rayton spectrograph lens; spectra of remote spiral nebulae photographed with roo-inch telescope; extremely short-focus lens designed by British Scientific Instrument Research Association; development of photographic amplifier by Stebbins and Whitford; use with roo-inch telescope; radiometers, etc.
\end{abstract}

A single decade includes two highly significant events in the endowment of research in America. On October I, I892, the University of Chicago, founded by John D. Rockefeller, opened its doors to students. About ten years later, on January 29, I902, the trustees of the Carnegie Institution of Washington, established by Andrew Carnegie, held their first meeting in Washington. The first of these events marked the inception of the long series of national and international gifts for research which we owe to the generosity of the Rockefellers. The initiation of the Carnegie Institution also meant, not merely one of several large endowments by Carnegie, but the inauguration of an extensive plan for the development of research, subsequently strengthened by his establishment of the Carnegie Corporation of New York.

The Carnegie Institution of Washington, through its organization of widely distributed laboratories and observatories and the substantial aid given to its research associates in many educational 
institutions, opened extraordinary opportunities for scientific investigation. The Rockefeller Foundation, the General Education Board, the International Education Board, and the Rockefeller Institute for Medical Research, with their broad and liberal policy, both national and international, proved admirably adapted to meet a wide variety of needs. The present undertaking, involving the cooperation of the Rockefeller and Carnegie groups, is but one of the countless results of their great gifts for the increase of knowledge.

The establishment of the Carnegie Institution's research departments at the most suitable sites, wherever found, could hardly fail to influence favorably the work of neighboring educational institutions. As a single example, the Mount Wilson Observatory may serve to illustrate this effect. In the northern part of California the Lick Observatory and the various departments of the University of California and Stanford University had long before reached a high plane, but in southern California little provision for research had been made prior to I904. Pasadena, where some of the offices, laboratories, and instrument shops of the Mount Wilson Observatory were erected in that year, soon recognized the possibilities emphasized by the Carnegie Institution of Washington. In the course of time the policy• of the California Institute of Technology, then known as Throop Institute, was completely remodeled. After the arrival of Dr. Arthur A. Noyes and Dr. Robert A. Millikan, an extensive plan of research in physics, chemistry, and other branches of science was developed at the Institute, and intimate co-operation with the Mount Wilson Observatory was begun. This rebirth of the Institute was made possible by gifts from many sources, both local and national. The interest of the Carnegie and Rockefeller boards having been thus aroused, their policy of encouraging such efforts came into play. Through their gifts, combined with those of many additional donors, the California Institute attained its present form. The foundation of the neighboring Huntington Library and Art Gallery, and its adoption of a research policy, added a third co-operating institution to the two already named. Pasadena thus became an active center of research and a favorable place, both climatically and intellectually, for the further development of similar undertakings. 
Such considerations doubtless determined the Rockefeller boards, which had previously made large grants to the California Institute, to offer it funds in 1928 for the construction of a 200 -inch reflecting telescope, together with all the buildings and equipment necessary to render this instrument as efficient as possible. Two conditions were made by the donors: the assurance of the active co-operation with the California Institute in this project of the Mount Wilson Observatory of the Carnegie Institution of Washington and the provision by the California Institute of an adequate endowment for the new Astrophysical Observatory. The president and Executive Committee of the Carnegie Institution, as well as the director of the Mount Wilson Observatory, quickly and cordially assented to the first of these conditions, while the trustees of the California Institute were no less prompt in agreeing to obtain an endowment.

Prior to the suggestion of President Wickliffe Rose of the International Education Board, the California Institute had not planned to establish a department of astronomy or astrophysics. The recent rapid development of astrophysics, however, and the great part in this development played by physics and chemistry, clearly made the most intimate possible co-operation between observatories and laboratories essential. A good beginning had already been made, but there was room for a still more effective union of effort. It was therefore decided to erect the Astrophysical Laboratory of the new Observatory next to the Norman Bridge Laboratory of Physics, in close proximity to the Gates Laboratory of Chemistry and not far from the Pasadena headquarters of the Mount Wilson Observatory.

The offer of the International Education Board was made at its annual meeting in May, I928. After a visit of Dr. Rose and Mr. Thorkelson to Pasadena and Mount Wilson, the trustees of the California Institute voted early in July to proceed at once with the undertaking. They accordingly appointed an Observatory Council, consisting of four members of the Executive Council of the Institute: Robert A. Millikan, director of the Norman Bridge Laboratory of Physics and chairman of the Executive Council; Arthur A. Noyes, director of the Gates Laboratory of Chemistry; Henry M. Robinson, chairman of the Security First National Bank of Los Angeles; and the writer, honorary director of the Mount Wilson Observatory and 
chairman of the Observatory Council, to take charge of the planning, construction, and operation of the Observatory. With the approval of President Merriam and Dr. Adams, several additional members of the Mount Wilson Observatory were authorized to join in the work. Accordingly, Dr. J. A. Anderson, of the Mount Wilson staff, was appointed executive officer of the Observatory Council. An Advisory Committee was established comprising Dr. Walter S. Adams (chairman), Charles G. Abbot, Ira S. Bowen, Paul S. Epstein, Edwin Hubble, Albert A. Michelson, Henry N. Russell, Frederick H. Seares, and Richard C. Tolman. To this Committee Professors T. von Karman, R. R. Martel, R. W. Sorenson, J. P. Buwalda, and W. H. Clapp have recently been added. Sir Herbert Jackson, director of the British Scientific Instrument Makers' Research Association, was appointed as research associate, and Francis G. Pease, of the Mount Wilson staff, and Russell W. Porter were named as associates in optics and instrument design. Sinclair Smith, of the Mount Wilson staff, and John Strong, formerly National Research Fellow in Physics have also joined in the researches involved in the project.

Dr. Walter S. Adams, who had attended all meetings of the Observatory Council from the beginning, was formally appointed a member of the Council in 1934, with the approval of the president and Executive Committee of the Carnegie Institution of Washington and the trustees of the California Institute. The president of the Carnegie Institution of Washington also appointed a co-operating committee, comprising Messrs. Adams (chairman), Hale, Hubble, and Seares, of the Mount Wilson staff, and Wright, of the Geophysical Laboratory of the Carnegie Institution of Washington, for the purpose of making a study of means through which the Carnegie Institution could contribute directly to aid in the furtherance of the 200-inch program. In the same year Captain Clyde S. McDowell, U.S.N., with long experience as a naval constructor, who had been given leave of absence from the Navy Department for this purpose, was selected as supervising engineer for the 200 -inch telescope.

In harmony with the plan previously drawn up by the writer at the request of Dr. Rose, it was decided that the new Astrophysical Observatory thus provided for should include (I) a 200-inch re- 
flecting telescope and other instruments, mounted at the most favorable high-altitude site to be found within effective working distance of Pasadena; (2) an Astrophysical Laboratory, on the campus of the California Institute, to serve as the Pasadena headquarters of the resident and visiting members of the research staff, the reduction of photographic and visual observations made with the 200-inch telescope and other instruments, the performance of experiments for the interpretation of these observations with the aid of apparatus supplementing that of the other laboratories of the California Institute and the Mount Wilson Observatory, the development of new instruments and methods of research, and the work of fellows and students in astrophysics: (3) Instrument and Optical shops, also on the campus of the Institute, for the construction of special apparatus and the figuring and testing of the mirrors and lenses required for the 200-inch telescope and other instruments.

The purpose of the present article is to describe in general terms the work thus far accomplished. It will be followed by other papers giving more detailed accounts of the various phases of the undertaking.

THE 2OO-INCH TELESCOPE

In designing the instrumental equipment of the new Observatory the chief points to be borne in mind are (I) our purpose to supplement, rather than to duplicate, the existing apparatus of the Mount Wilson Observatory and the California Institute; (2) to multiply the efficiency of all our instruments not merely by increase in size but by every possible improvement in methods of design and construction and especially by the development of new auxiliary apparatus; and (3) to render the results of these investigations available at once to other observatories and research laboratories, where their immediate utilization might lead to new advances, long before the completion of the 200-inch telescope. As the annual reports of the Mount Wilson Observatory sufficiently indicate, this hope has been amply justified.

Our experience at Mount Wilson clearly demonstrates that the new telescope should be an equatorial reflector of large angular aperture, so mounted as to permit observation at the principal focus of the 200-inch mirror, at the Cassegrain focus below the large 
mirror, and at the coudé focus within a constant temperature laboratory south of the polar axis. These possibilities exist in the case of the roo-inch Hooker telescope, but this instrument cannot reach the region surrounding the north pole (its farthest range in north declination is $63^{\circ} 58^{\prime}$ ), observation at its principal focus is difficult, and the time required to change the "cages" carrying the Newtonian and the two Cassegrain mirrors affects materially the observing program.

As for the optical parts, it was evident that in passing from a 100inch to a 200-inch mirror a new type of disk would be required. The Ioo-inch mirror disk, made at St. Gobain of the best glass then available (ordinary plate glass), gives excellent results under almost all conditions. But even with the improved support system recently designed by Pease, it still shows at times sufficient change of figure with temperature to preclude the use of similar glass for a mirror of 200 inches aperture. The first step in the new undertaking therefore involved a comparative study of different means of making a suitable 200-inch disk.

Mirror disks.-After excluding one or two types of mirror disks which we and our advisers unanimously agreed to be unsuitable, the following possibilities remained: fused silica; some form of Pyrex glass; stainless steel or some other metallic alloy; and a special type of metallic disk, with a thin layer of glass of the same coefficient of expansion securely fused to its surface, proposed by the Philips Lamp Works of Eindhoven, Holland. Of these various materials, fused silica has the lowest coefficient of temperature expansion, and as Dr. Elihu Thomson and his associates had already made excellent small mirror disks of fused silica for use in telescopes, we arranged with the General Electric Company to have this investigation continued by Dr. Thomson and Mr. Ellis at the Thomson Research Laboratory at Lynn, Massachusetts. I trust they will publish a full account of the methods they devised and the results they accomplished. Only a brief statement regarding this long research is therefore included here.

In its earlier stages the process consisted in fusing a mass of nearly pure quartz sand in a circular electric furnace comprising the mold. The disk thus obtained, which contained a great number of bubbles, 
was then ground to the approximate curvature desired and coated to a sufficient thickness with a layer of perfectly transparent fused quartz, free from bubbles. This layer was produced by spraying pure crystalline quartz, in finely granular form, on to the surface of the hot disk by means of an oxyhydrogen flame. Excellent mirror disks up to a diameter of 25 inches were produced in this way. Unfortunately, however, it finally became evident that the much larger disks required could not be made by this process.

With their well-known resourcefulness, Dr. Thomson and Mr. Ellis were not blocked by the difficulties thus encountered, which were due to the extremely high melting point of pure crystallized silica. They accordingly devised multiple spray burners of large size, suitable for laying down the entire disk within an electrically heated oven. The designing of suitable burners, the selection, granulation, and special treatment of quartz of the requisite purity, and the problem of supplying gas in sufficient quantities involved long and difficult researches. Finally they succeeded in producing a solid disk of fused silica with a diameter of about 66 inches and a thickness of $I_{5}$ inches. The extraordinary qualities of fused silica are shown by the fact that this disk was cooled within nine days almost to room temperature without cracking. During the final stages of the process, however, the cover of the furnace was removed too soon through some misunderstanding of the workmen, and a radial crack developed, extending partially through the disk. In a second attempt an unbroken disk was obtained, but this was rendered unsuitable for optical purposes by pieces of fire brick falling from the cover of the furnace. Finally, in an effort to recoat one of these disks with pure silica, a failure at midnight in the electric-power supply resulted in another disaster.

Although it seemed probable that this process might ultimately lead to the production of suitable large blocks of fused silica, we reluctantly abandoned the attempt in the autumn of I93 I because of the very great cost, as then estimated, of the disks needed for our purpose.

Fortunately, our next line of attack was so strong that we could rely upon it with confidence. For many years the staff of the Geophysical Laboratory of the Carnegie Institution of Washington, 
under the direction of Dr. Arthur L. Day, had been engaged in developing new types of glasses, of which Pyrex is the best known. Under the leadership of Dr. Day, these glasses have been manufactured by the Corning Glass Works at their factory in Corning, New York. Every housewife is familiar with the remarkable qualities of the Pyrex glass used for cooking utensils, as its very low coefficient of expansion permits it to be subjected to rapid change of temperature without cracking. Glasses of this general type thus offer qualities for telescope disks far surpassing those of the glass used for the Ioo-inch and all other large telescope mirrors.

During the last ten years we have become familiar with the good performance of ordinary Pyrex in the solar telescopes on Mount Wilson and my laboratory in Pasadena. In the case of the 200-inch mirror, however, it was necessary to know whether any danger of devitrification might arise during the period of annealing and also to solve various other problems involved in its manufacture. A long series of new investigations was accordingly undertaken at the Research Laboratory of the Corning Glass Works, under the personal supervision of Dr. Hostetter and Dr. McCauley. These studies led to the development of special methods of casting, preliminary cooling, and annealing, which proved very successful in the case of a 6o-inch disk made at Corning in July, 1932. This disk, after careful consideration, had been designed by Dr. Pease and the Corning research staff with a ribbed back, which affords the necessary stiffness. ${ }^{\text {I }}$ It also permits the use of a greatly improved support system, besides very materially diminishing the weight and the annealing time, as contrasted with a solid disk of the old type. Since the casting of this 6o-inch disk a new Pyrex glass of still lower coefficient of expansion has been thoroughly tested at Corning, with highly satisfactory results. The many superior qualities of this glass include reduced annealing time and complete freedom from any danger of devitrification. An annealing oven for the 200-inch disk and the special apparatus for casting and handling disks of large dimensions were also built. The I 20 -inch disk, required for testing the 200 -inch mirror during the process of figuring, was then cast and annealed

\footnotetext{
${ }^{\top}$ A smaller ribbed coelostat mirror, made at Corning of Pyrex glass, has successfully passed very severe tests in our Optical Shop in Pasadena.
} 


\section{PLATE V}

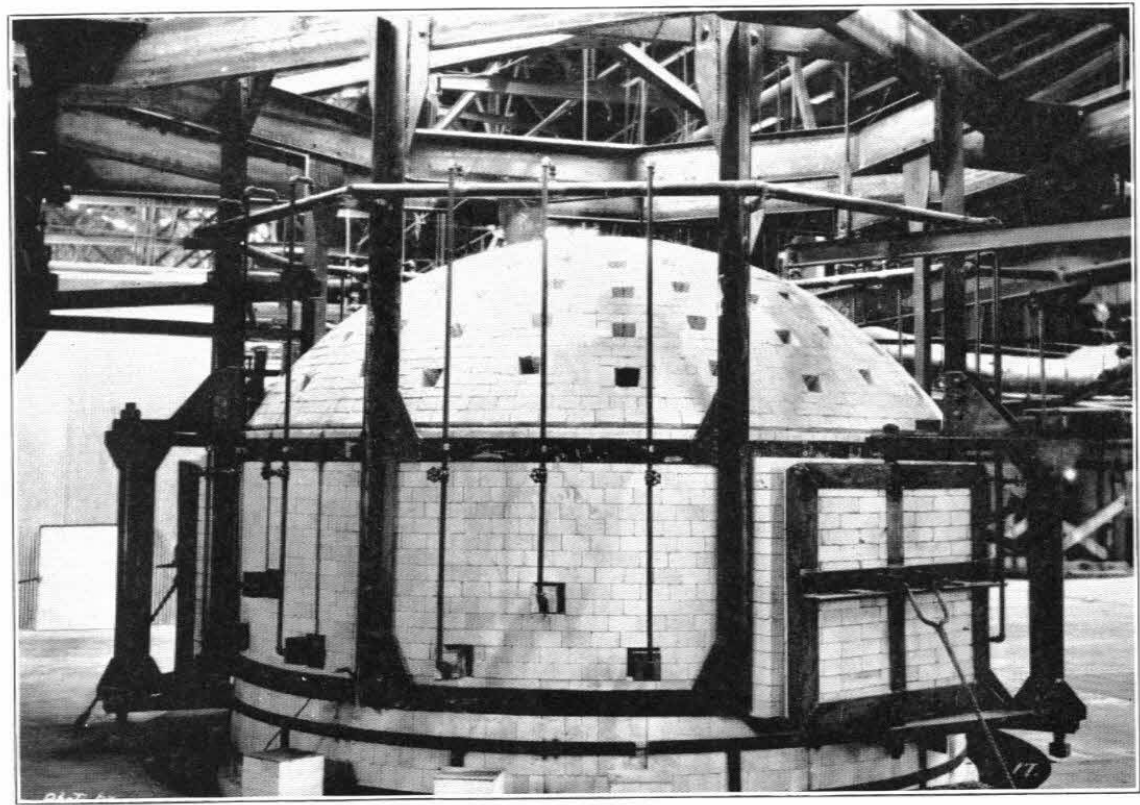

FIG. I.-Beehive oven used to heat 120 -inch disk and mold during the casting operation (Corning Glass Works).

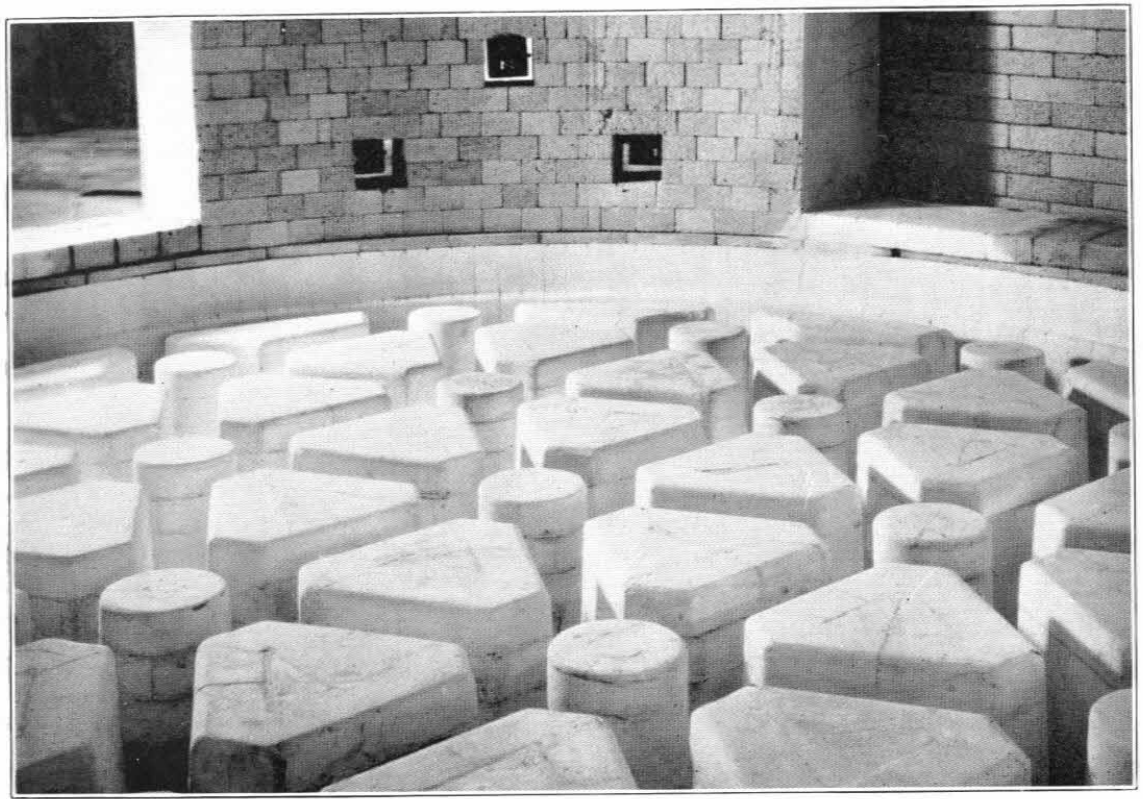

FIG. 2.-Mold for I 20 -inch disk, showing cores for circular holes and triangular openings between ribs. 


\section{PLATE VI}

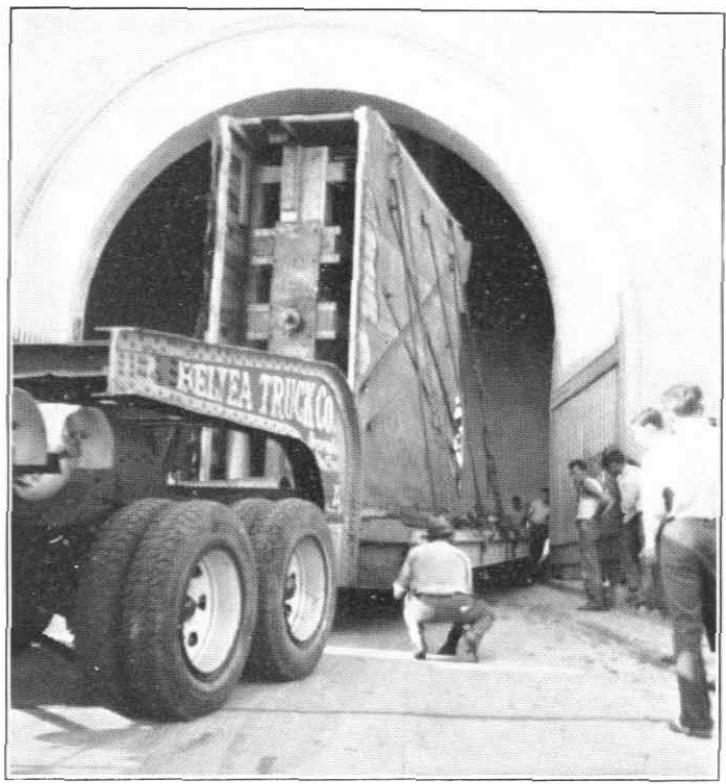

FIG. I. - Arrival of I 20 -inch disk at the Optical Shop, California Institute of Technology.

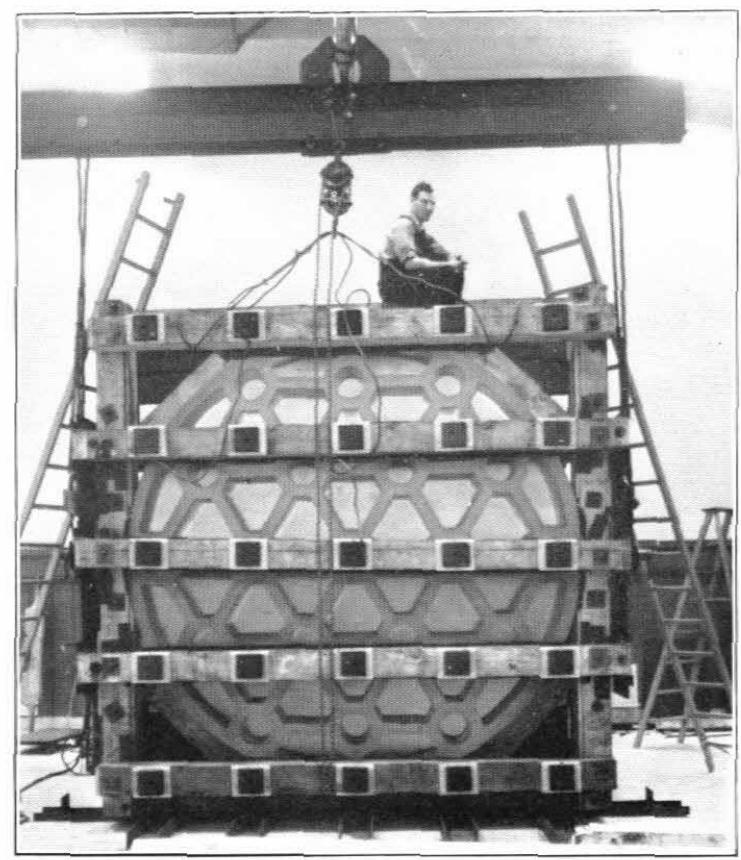

FIG. 2.- I 20 -inch disk in crate 
PLATE VII

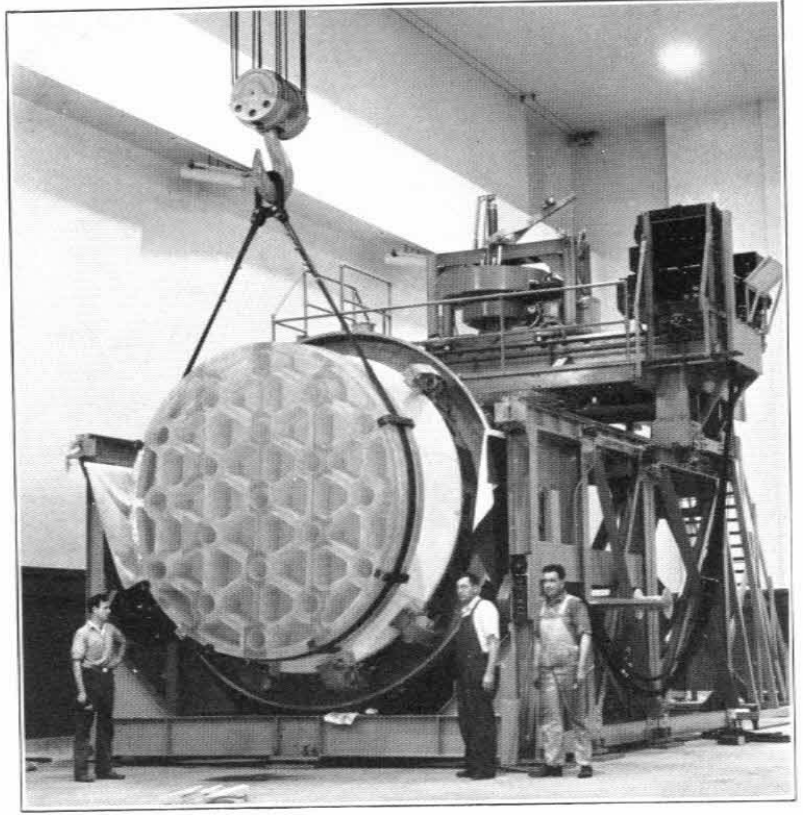

FIG. I.-I 20 -inch disk being placed on turntable of grinding machine.

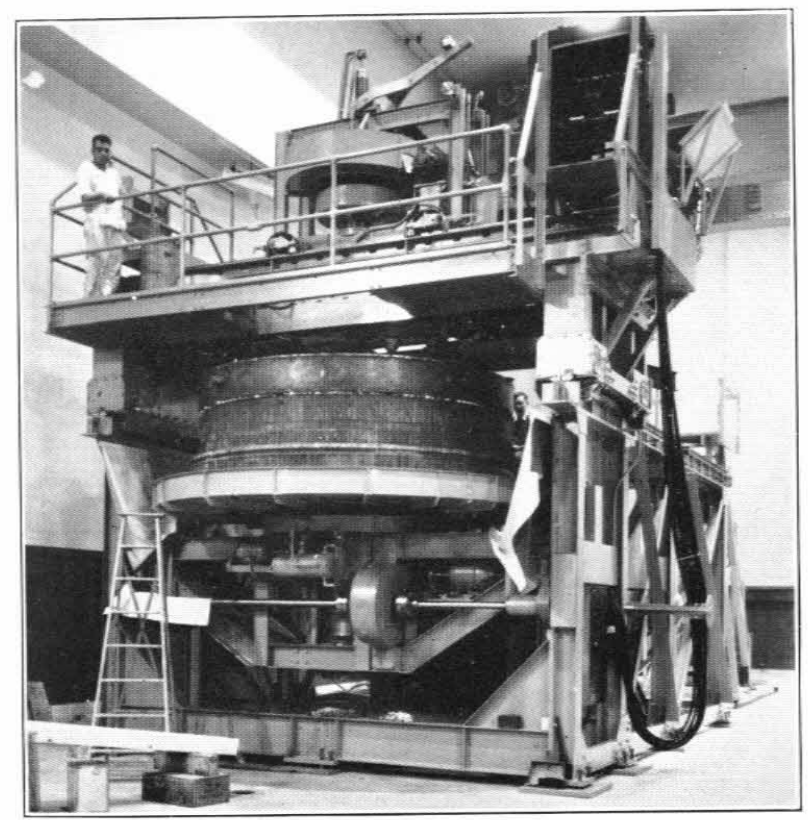

FIG. 2.-I 20 -inch disk on grinding machine, with grinding tool in place. 
PLATE VIII

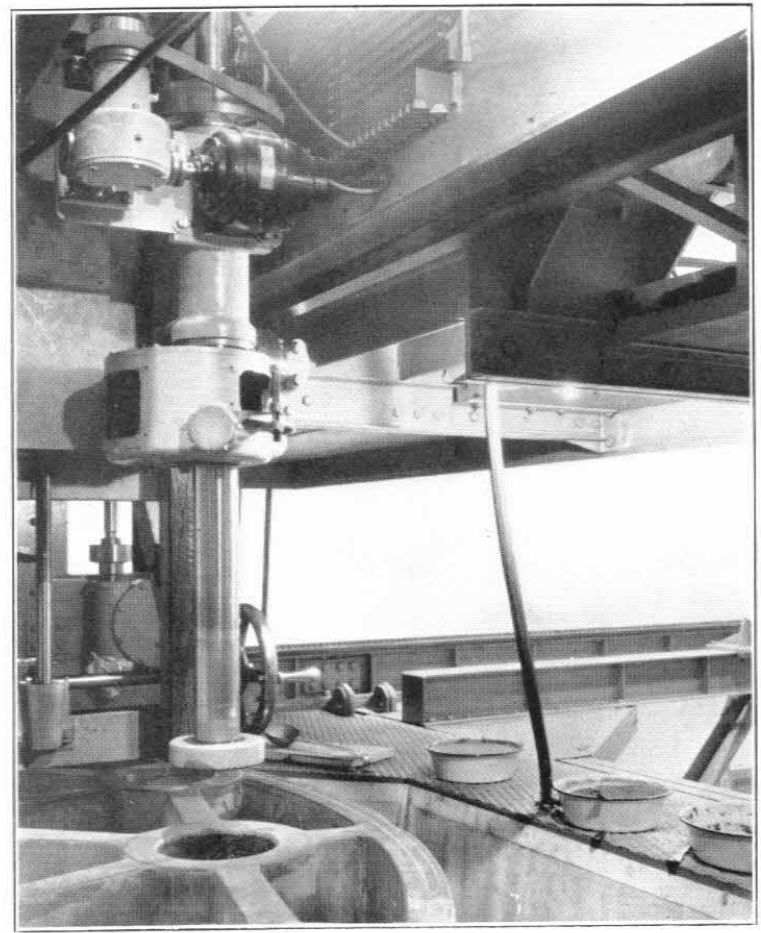

FIG. I.-Apparatus for grinding pockets in back of 120 -inch mirror for elements of support system (also used as edge-grinder).

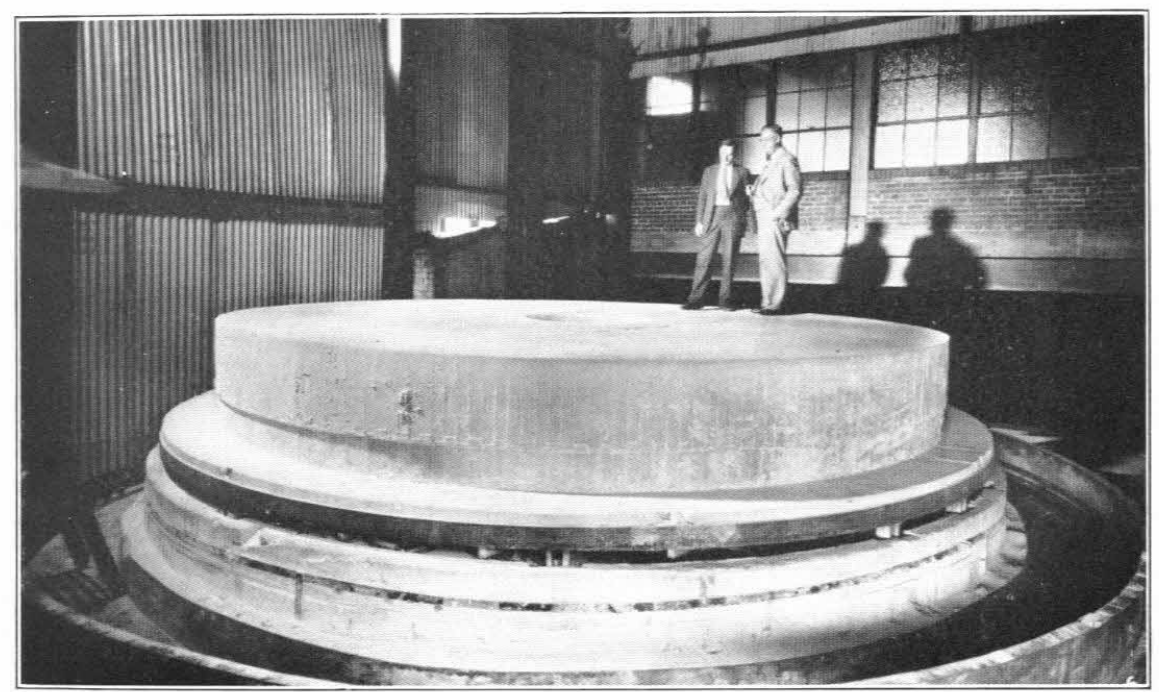

FIG. 2.-The first 200-inch disk at the Corning Glass Works 
PLATE IX

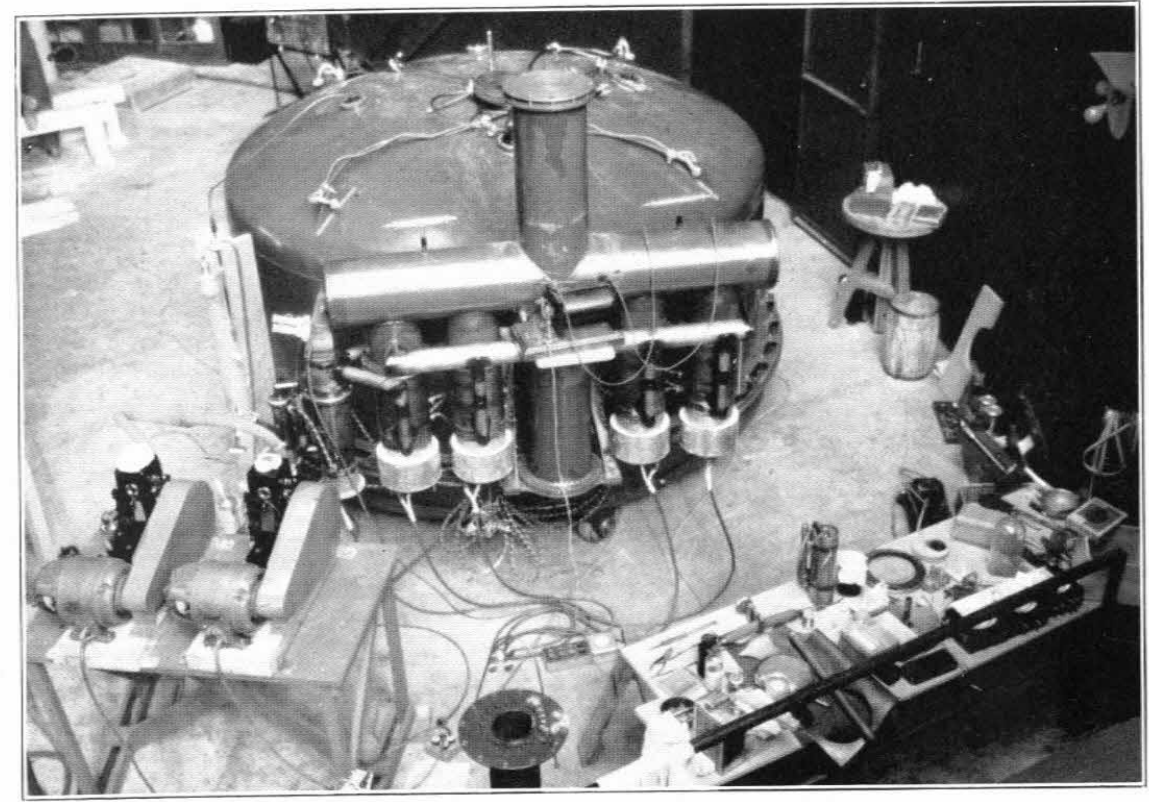

FIG. I.-The aluminizing chamber and pumps

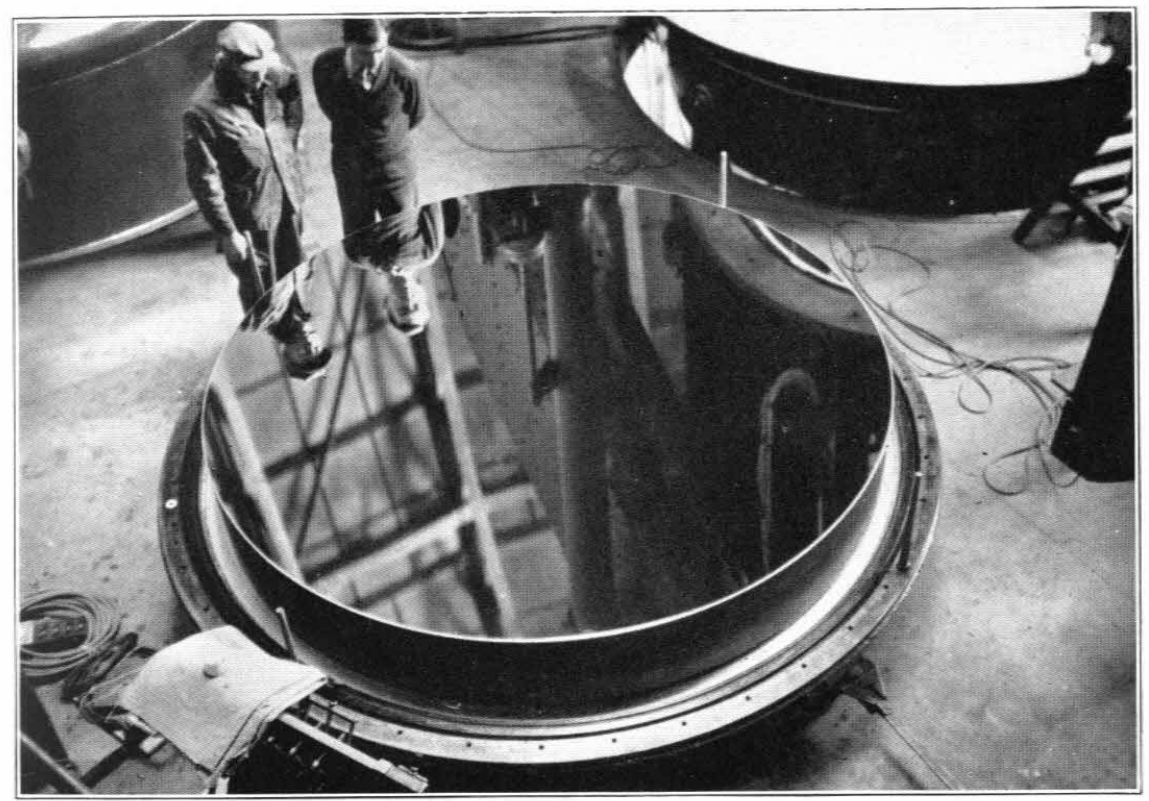

FIG. 2.-The roo-inch Hooker telescope mirror after aluminizing 
with great success (Pls. V-VIII). It is now being figured in our Optical Shop in Pasadena.

After the completion of the 200-inch mold and the casting of several large telescope disks for other observatories, a 200 -inch disk was cast for us on March 25, I934. The glass was poured from steel buckets containing 750 pounds each, and many hours were required to fill the mold, as only about one-half of the glass actually entered the mold from each bucket. ${ }^{2}$ The extremely high temperature of the glass caused some of the supports of the mold material to break down near the end of the pouring process. Thus some portions of the mold rose into the molten disk. After a subsequent heating these were scooped out and the disk recooled. Although considerable work would be necessary to restore the symmetry of the rib system on the back of the mirror, this disk is being retained for possible use in case of any accident to its successor (Pl. VIII, Fig. 2).

The second 200-inch disk was poured with perfect success on December 2, I934, into a greatly improved mold designed by Dr. McCauley, of the Corning Glass Works, who also designed the electric control system for gradually lowering the temperature of the disk during the annealing process, which will be completed before the end of the present year.

Reference has already been made to two other possible types of mirror disk. Through the co-operation of Dr. John Johnston, director of the Research Laboratory of the United States Steel Corporation, we have had an opportunity to examine several forms of stainless steel. These samples, and some others received from different sources, are of great optical interest, because of their heat conductivity, the permanent luster of their surfaces, and their high coefficient of reflection in the ultra-violet. Here they resemble speculum metal, and recall the fact that comparatively little stellar spectroscopic work has been done with large telescopes in the far ultra-violet since the early researches of Huggins. A 200 -inch metallic disk probably could be made and subjected to special heat-treatment at relatively small expense, if it were needed.

An 8-inch glass-on-metal mirror, made for us by the Philips

${ }^{2}$ G. V. McCauley, "Making the Glass Disk for a 200 Inch Telescope," Sci. Mo., 39, 79, 1934 . 
Lamp Works, gave such remarkable results when subjected to sudden and violent heating while under optical test that we have obtained a 36 -inch disk from this firm. This is intended for use with the vertical coelostat telescope of our new Astrophysical Laboratory. The thin glass surface, and the high heat conductivity of its ribbed metallic backing, fused to glass of the same coefficient of expansion, may afford important advantages for solar work.

Aluminum mirror surfaces.-In this connection reference should be made to the very successful experiments made by Dr. Strong, of the California Institute; Dr. Williams, of Cornell University; Dr. Edwards of the University of California at Los Angeles; and others in coating glass mirrors with metallic films of various kinds in vacuo. Some beautiful surfaces thus made by Dr. Strong in our Optical Shop are now in use at the California Institute, the Lick Observatory, and the Mount Wilson Observatory. Aluminum films are especially desirable from an optical point of view. Their coefficient of reflection is high over a long range of wave-length, they are very homogeneous and completely free from the thousands of minute scratches which produce so much diffuse light on all burnished mirrors, and they do not tarnish like silver. Dr. W. H. Wright, of the Lick Observatory, informs me that the 36-inch mirror of the Crossley reflector, after being coated here with aluminum by Dr. Strong, shows no measurable change in total reflecting power after the lapse of a year. Its surprising extension of stellar and nebular spectra in the ultra-violet has been illustrated by Dr. Wright in the Publications of the Astronomical Society of the Pacific. Very recently, with a large vacuum chamber and pumps built in our Instrument Shop at the California Institute, Dr. Strong has successfully coated the 6o-inch and the roo-inch mirrors on Mount Wilson with aluminum (Pl. IX). Their increased reflecting power and freedom from diffuse light are remarkable, as shown, for example, by photographs of such unequal double stars as Sirius. We therefore expect to use this process for the 200 -inch mirror.

The 200-inch telescope mounting.- Telescope mountings vary widely in their requirements. Visual and spectroscopic observations do not suffer greatly from flexure in the mounting, but the demands of direct photography are much more stringent. We have studied 
several possible designs for the mounting of the 200-inch telescope, and our investigation of the problem is still in progress. The engineers whom we have consulted call for two points of support, on opposite sides of the tube, and then endeavor to attain the greatest possible degree of rigidity conformable with the requirements of the optical design and the necessary range of motion in right ascension and declination.

As we wish to reach all parts of the sky visible in our latitude and to provide for the various optical combinations already mentioned, we have selected two possible mountings for rigorous comparison: the well-known fork type, first used on a large scale by Lassell for his 4 -foot Malta reflector; and the English yoke type, illustrated in one form by the Ioo-inch Mount Wilson reflector. A yoke mounting, in another form suggested by Anderson, Edgar, and Serrurier, was recently embodied in a model built in our shop. The advantages of this modified yoke type, some of which were also included later in a modified fork type, are as follows:

The telescope tube, instead of being hung near its lower end between the arms of the yoke or fork, has its declination axis not far below its center. This increases its stability, and allows the use of a dome of much smaller relative diameter than the domes of the 6oinch or 100-inch reflectors on Mount Wilson.

The increased stability of the tube will allow the observer to be carried in a cartridge-shaped house at its principal focus, thus permitting the elimination of the large Newtonian mirror.

The troublesome and time-consuming task of changing the huge "cages" carrying the Cassegrain and Newtonian mirrors will be eliminated. There will be two Cassegrain mirrors, mounted in a tube extending a short distance below the principal focus of the 200inch mirror. Each of these mirrors can be instantly turned into position by means of a worm gear, driven by an electric motor.

One of the convex mirrors will give at the secondary focus, just below the hole in the 200 -inch mirror, a large and sharply defined star field, with a focal ratio of $f / \mathrm{I} 6$ (equivalent focal length $=3200$ in.). A stellar spectrograph with one, two, or three prisms will be mounted here, or a double-slide plate-carrier can be quickly substituted for the spectrograph when desired. 
The same convex mirror, used in conjunction with a plane mirror standing at an angle of $45^{\circ}$ with the axis of the telescope tube, will send the converging beam through the hollow declination axis to a totally reflecting prism, mounted before the slit of a long-focus grating or prism spectrograph. This spectrograph will be hung within a large hollow cylinder, supported parallel to the polar axis and so geared that the spectrograph slit will always remain vertical. A second cylinder on the opposite side of the polar axis will be provided to carry a radiometer or any other auxiliary instrument which must remain in a vertical plane. This ingenious schene is a valuable feature of this form of mounting.

Another Cassegrain mirror, aided by the plane mirror suitably orientated, will send the converging beam toward the south pole through the hollow polar axis into a constant-temperature chamber, as in the case of the roo-inch telescope. This will permit the use of a fixed spectrograph or other auxiliary apparatus of any focal length desired.

On account of the importance of securing a completely satisfactory mounting and dome, a large amount of time and effort have been devoted to this study. A preliminary fork design made in Pasadena by Mr. E. P. Burrell, of the Warner and Swasey Company, in conjunction with our local group, was followed by the modified yoke design already mentioned, and then by a second fork design. Captain McDowell has just completed an extensive investigation of constructional facilities in various parts of the country, and a final comparative study of the problem, calling in the aid and experience of many able engineers and men of science, is now under way. ${ }^{3}$

It will probably be advisable to include within the lower part of the building supporting the dome a small instrument repair shop, several dark rooms, a laboratory for adjusting and testing instruments, and some other requirements.

\section{SITE}

The question has sometimes been raised whether the 200-inch telescope would not be more useful in the southern hemisphere. As

${ }^{3}$ Since this paper was written, and after a complete analysis of the various types by the firm of Lessells \& Karelitz, Professor Timoschenko, and many other leading engineers, the Advisory Committe and the Observatory Council have voted unanimously to adopt the yoke type of mounting. 
all astronomers will recognize, a very large telescope, having a small field, should be rarely employed for scouting purposes and never for work within the ready range of smaller instruments. It must be devoted almost exclusively to the study of selected objects. Thus the vastly greater knowledge of stars and nebulae acquired during centuries of observation north of the equator is precisely what is needed in making adequate selections for more intensive study. Moreover, nearly two-thirds of the nearest extra-galactic nebulae, offering the greatest possibilities of research, can be observed only from a northern station. The importance of a detailed investigation of such unique spirals as the Great Nebula in Andromeda and Messier 33, with the highest instrumental power, cannot be overstated. As for the brightest stars, the only ones available for spectroscopic examination with very high dispersion, three-quarters of them are accessible from Mount Wilson. Then, too, our existing knowledge of tens of thousands of faint stars and millions of very remote nebulae, derived from many years of work with the largest existing telescopes, provides the necessary means of selecting suitable objects for further investigation with the 200-inch telescope. Finally, the southern hemisphere can at present furnish no co-operating research institutions comparable in staff and equipment with the California Institute and the Mount Wilson Observatory.

It is, however, very desirable that much work be done south of the equator with large telescopes, thus gradually preparing the way, as in the north, for another instrument as large as the 200-inch telescope.

A long study of meteorological, topographical, and astronomical conditions, reinforced by more than thirty years of experience at Mount Wilson, leaves no room for doubt regarding the advantages of the southwestern corner of the United States as the site for a $200-$ inch telescope. Its latitude gives access to the whole of the northern heavens, as well as a broad zone south of the celestial equator. Its mountain ranges afford easy means of escape from the dense air of the lower atmosphere, which not only produces poor images but absorbs and scatters much light. On some of the mountains of southern California the daily range in temperature is remarkably low, while the annual range is moderate. A large daily range is very 
objectionable, because of the difficulty of preventing distortion of the telescope mirrors and its effect on the telescope mounting and auxiliary instruments. A large annual variation is also to be avoided, as this means low winter temperatures and greatly reduced efficiency of the observer. The average wind velocities, as shown by the Mount Wilson and other mountain records, are also very low, while the comparative freedom from clouds permits observations to be made on a large percentage of nights during the year. All these favorable conditions are readily explained when the paths of the principal storms in the United States are taken into account.

Dr. Wickliffe Rose repeatedly expressed the hope that a site easily accessible from Pasadena would be chosen, so as to permit the readiest co-operation between the staffs of the Mount Wilson Observatory and the California Institute. Our experience in the past and our recent astronomical and meteorological studies confirm this view. In fact, if it were not for the great increase of electric lights in the San Gabriel Valley since our first occupation of Mount Wilson, it is probable that a site adjoining the Ioo-inch Hooker telescope might prove most suitable. While it is true that even now these lights affect slightly but a few classes of work, and then only in the case of objects south of the zenith, they would be more troublesome with the 200-inch telescope on such occasions because of its larger aperture.

In a later article Dr. Anderson, who has been in immediate charge of our recent site investigation, will describe in detail the special instruments employed, the simultaneous tests of seeing made by several trained observers at many different points, the visual, photographic, and photo-electric cell measurements of sky brightness, and the conclusions derived from airplane flights.

In general, it may be said that the Tehachapi Mountains form an important barrier against the greater cloudiness and increased rainfall to the north. South of this range there is also decreased atmospheric disturbance because of greater distance from the centers of the most typical cyclonic storms moving eastward from the Pacific Ocean near the Canadian border. Local conditions, however, may affect particular sites. Thus the mountains at the eastern end of the San Gabriel Valley are very much more subject than Mount Wilson 
to the thunderstorms that may interfere so seriously with summer observations still farther east. On the other hand, these mountains serve as a most advantageous wall between the desert and the sea, affording admirable protection to many promising mountain sites. After a five-year study of the best of these, all exceptionally free from local atmospheric disturbances and the effect of city lights, we have provisionally selected a nearly level tract of land on the summit of Palomar Mountain, which lies about 93 miles southeast of Pasadena and 50 miles north of San Diego.

In his valuable report to the Carnegie Institution of Washington on possible sites for an astrophysical observatory, the late Professor W. J. Hussey, then of the Lick Observatory, gave an excellent survey of the atmospheric conditions in southern California. ${ }^{4}$ Equipped with a portable 9-inch Clark refractor, he examined several mountain sites lying within the region extending from the Mexican border to the ranges lying north and east of Los Angeles, and added many useful comments on the topographical and climatic conditions in this portion of the Southwest. After following up his telescopic tests over a much longer interval of time, I fully agreed with his tentative selection of Mount Wilson, where I began work in the winter of I903-1904.

Among other sites inspected by Professor Hussey was Mount Palomar (latitude $33^{\circ} 2 \mathrm{I}^{\prime} 2 \mathrm{O}^{\prime \prime}$, altitude about 6roo ft.). However, after long consideration, he thought Mount Wilson would be preferable to Palomar, partly because of its easy accessibility from Los Angeles and Pasadena. At that time, in the absence of motor cars and roads worthy of the name, Palomar was very difficult to reach. Moreover, Hussey had ascended the mountain from a station on Cuyamaca, about 30 miles toward the southeast, where the conditions were poor and the desert near. Impressed by his unfavorable tests at Cuyamaca, he feared similar atmospheric disturbances at Palomar, and did not take his telescope there, though he regarded it as the most promising site in San Diego County.

We have no reason to regret Hussey's choice, as Mount Wilson has proved to be an admirable site, and even since the great increase of population in the San Gabriel Valley and the consequent multiplica-

${ }^{4}$ Year Book No. 2, Carnegie Institution of Washington, December, I903. 
tion of electric lights, we would not wish to move the Observatory. The choice of a site for a telescope of the large linear and angular aperture of the 200-inch is, however, a different problem under present conditions. The darkest possible sky is required for longexposure direct photography at the principal focus of the large mirror, in addition to such low wind velocity and other good qualities as Mount Wilson enjoys.

Through the courtesy of Dr. Marvin, lately chief of the United States Weather Bureau, several sets of recording instruments were loaned to us for a considerable period. One of these sets was kept in operation on Palomar for five years, so that we are now well informed regarding the meteorological conditions. Many tests of seeing, made by several skilled observers of the Mount Wilson staff, have also been made there. These show that the average seeing differs very little from that at Mount Wilson, though Ellerman frequently found the Palomar seeing superior. The average wind velocity and rainfall are also similar at the two sites. As for accessibility, we are promised by the San Diego County authorities a broad and well-surfaced road, of about half the grade of the Mount Wilson Toll Road, and the motor trip from Pasadena can now be quickly made over perfect concrete routes. If other necessary conditions are fulfilled, and if we can be certain of permanent protection from all appreciable sources of disturbance, the 200-inch telescope will presumably be erected on Palomar Mountain. But other excellent sites are available.

Before outlining the studies of auxiliary apparatus and methods hitherto made, brief descriptions of the buildings and instruments erected on the campus of the California Institute may be given.

THE ASTROPHYSICAL LABORATORY

Our experience at the Mount Wilson Observatory has demonstrated beyond question the many advantages of having the headquarters of its staff in Pasadena. The mild climate of the San Gabriel Valley, the possibility afforded the various families to share in the amenities of an attractive residence city, the facility of cooperation with the California Institute, the change of scene enjoyed by the observers in dividing their time between the mountain and 
the town all contribute materially to greater efficiency. Furthermore, the members of the laboratory staff, computing division, and instrument shops, who rarely require access to the telescopes on the mountain, can work to much better advantage in Pasadena.

Similar conditions will apply in even greater degree to the new Astrophysical Observatory. Its Astrophysical Laboratory, standing in close proximity to the Norman Bridge Laboratory of Physics, the Gates Chemical Laboratory, and the many other related departments of the California Institute, could hardly be more favorably situated (Pl. X, Fig. I). Designed and equipped so as to supplement these departments, as well as those of the Mount Wilson Observatory a few blocks away, it embodies many ideas generated in both institutions during the last thirty years.

In planning the building, which was designed by the Goodhue Associates in harmony with the general type of architecture adopted by the late Bertram Goodhue for the California Institute, we have profited in many respects by this experience. One of the excellent features of the Bridge Laboratory, for instance, is its extension under ground, where the constancy of temperature is so useful. As will be seen from the cross-section shown in Figure I, the Astrophysical Laboratory has two and one-half stories under ground, in addition to the rectangular well ( $\mathrm{I}_{3}$ by 30 by $60 \mathrm{ft}$.) containing the 75 -foot spectrograph and other instruments. Springing from the massive reinforced concrete walls of this well, at a point 28 feet below the ground level, is the octagonal steel and concrete tower, extending to a height of 68 feet and free from contact with the floors or walls of the building. This tower carries the coelostat telescope (Pl. X, Fig. 2), with plane mirrors 36 and 30 inches in diameter, the second of which sends the solar beam nearly vertically downward, where it falls upon a 26 -inch concave mirror 47 feet below the second flat of the coelostat. This concave mirror returns the beam to one of three smaller convex mirrors of fused silica, so mounted that each can be turned into position above the vertical axis of the 75 -foot spectrograph. The system is therefore that of the "skew Cassegrain," which I have used successfully in my Solar Laboratory in Pasacena. These convex mirrors give solar images $22, \mathrm{I}_{4}$, and 7 inches in diait- 


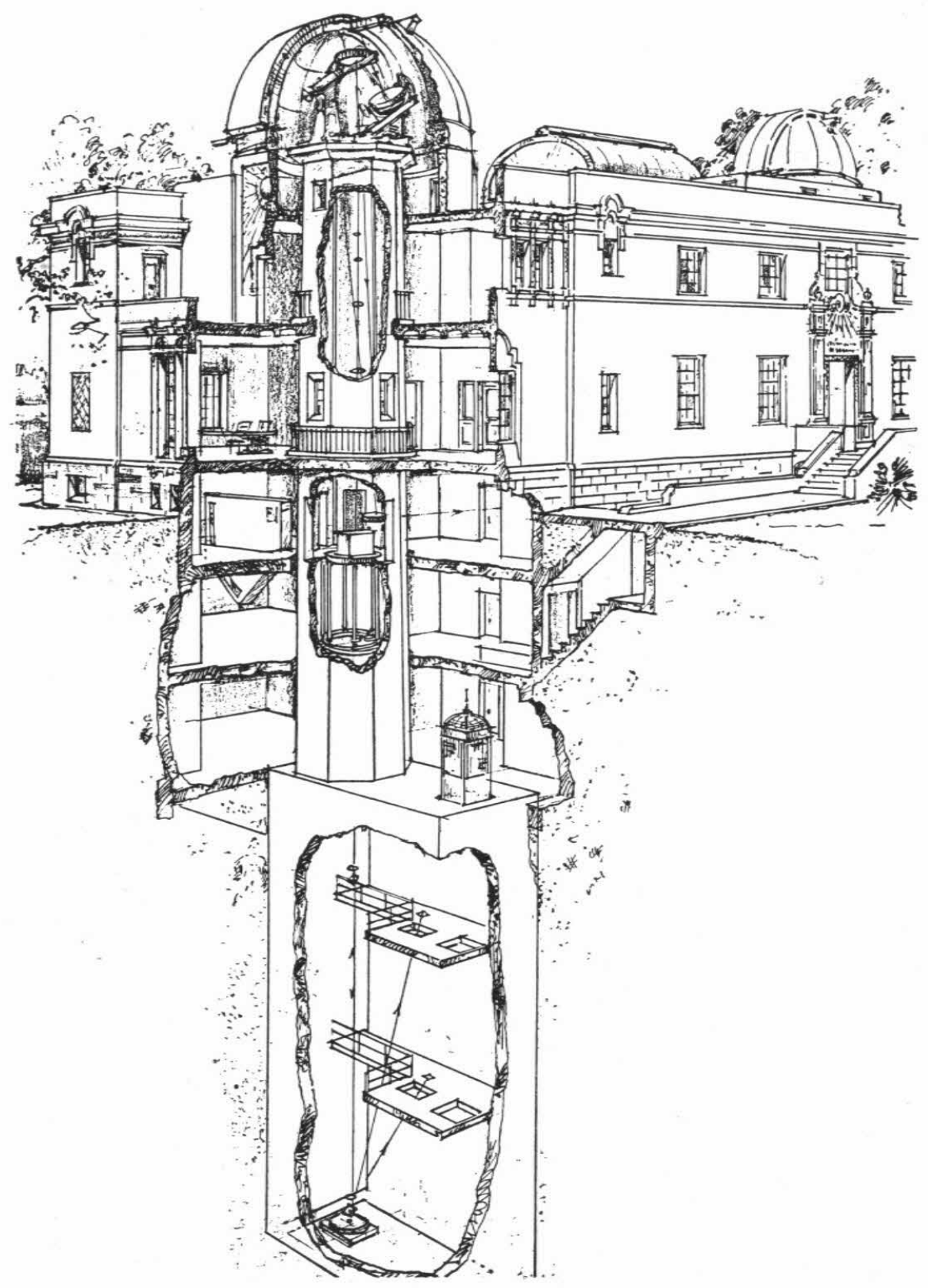

Section of the Astrophysical Laboratory 
PLATE X

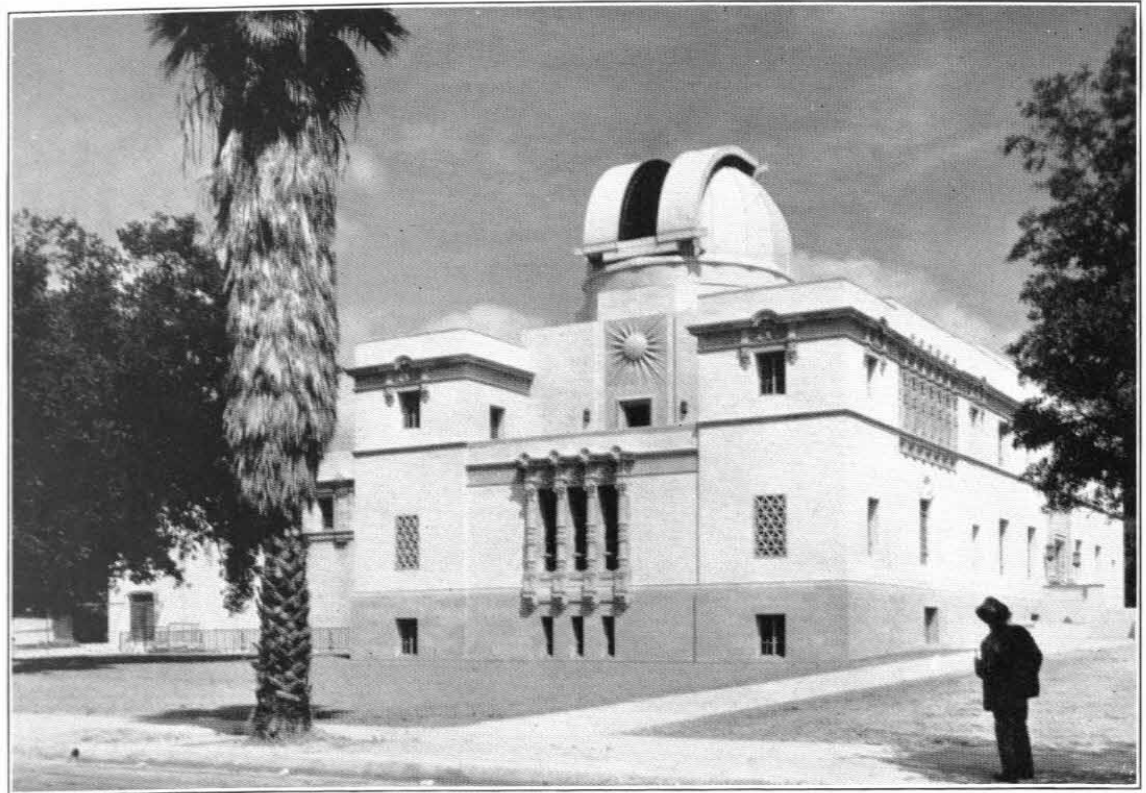

Fig. I.-Astrophysical Laboratory at the California Institute

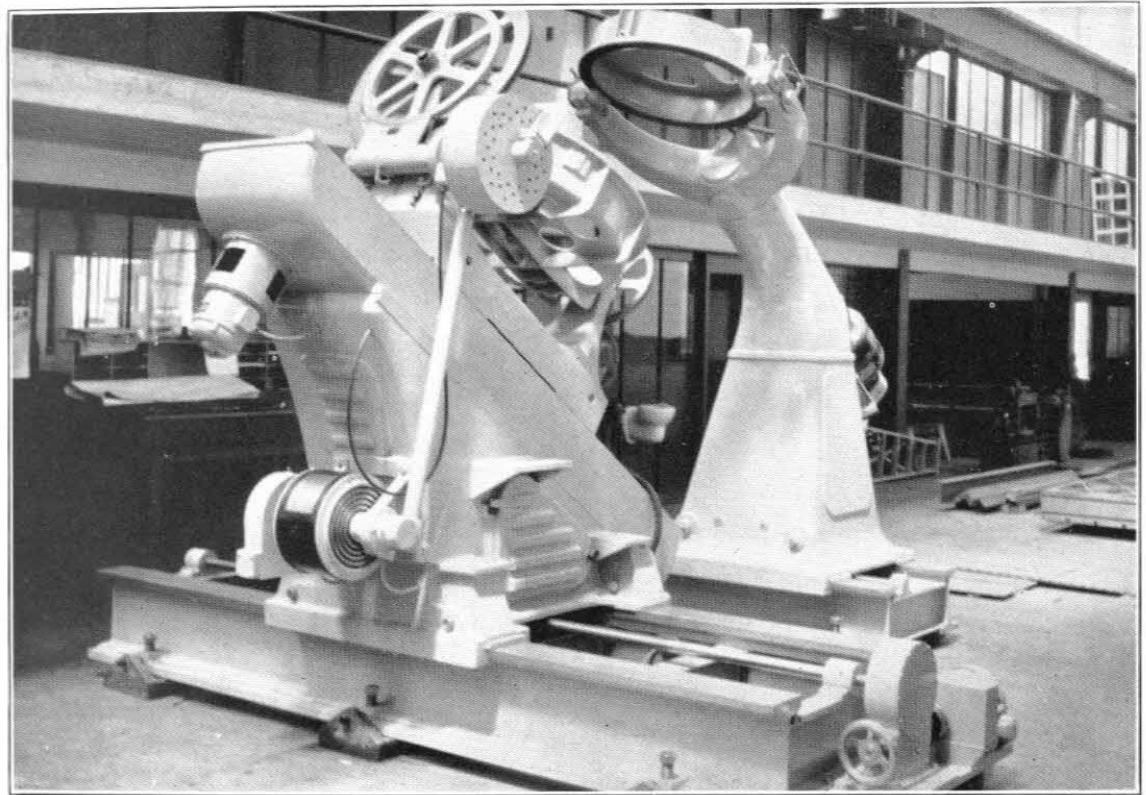

FIG. 2.-Coelostat mounting for Astrophysical Laboratory 
eter, respectively, on the slit of the spectrograph. With other optical combinations smaller images of the sun, for visual observation with a spectrohelioscope or photography with a spectroheliograph, both mounted in the well, can also be obtained. No detailed description of this spectrographic outfit need be given here, but it should perhaps be added that its design permits great flexibility of arrangement, including Littrow combinations 8 inches in aperture of 38 feet and 75 feet focal length, respectively - as well as other arrangements such as a 75 -foot collimator combined with a ro-foot camera, an I8-foot camera, a 30 -foot camera, etc. In these combinations large plane gratings or liquid prisms may be used, in accordance with the requirements of the investigation in progress. The various levels of the spectrograph well are easily reached by means of a small elevator. Needless to say, the entire massive head of the spectrograph can be rotated in position angle, as well as the grating or prism support beneath it in the well. Of course, provision is also made for such attachments as the special polarizing apparatus required in the study of solar magnetic phenomena. The auxiliary apparatus also includes a large magnet for work on the Zeeman effect; an electric furnace; and arcs, sparks, and vacuum tubes, with the necessary controls and transformers. Mounted for use with the solar image, there will also be a special interferometer spectrograph, designed to supplement the present interferometer of the Mount Wilson Observatory. This brief account of the vertical coelostat telescope and its auxiliaries may suffice for the purpose of a preliminary article. As for the general design of the Astrophysical Laboratory, the width of the main building (east and west) is 57 feet, while its length is I 28 feet (Fig. I). There is also an extension at the northeast end, chiefly underground, $4 \mathrm{I}$ feet wide and $5^{\mathrm{I}}$ feet long. This contains the motor generators and other machinery, ventilating apparatus, etc.

In addition to the domes and special housings for its larger instruments, provision is made for the offices of the staff and research students, computing rooms, dark rooms, a seminar room, etc. These are distributed as follows:

On the roof are the 23 -foot dome of the coelostat telescope, a rolling house covering a "solar furnace" (consisting of nineteen 24-in. lenses and the same number of condensing lenses, equatorially 
mounted, which concentrate the solar rays at an immovable focus), a spectrograph for use with the solar furnace, a I 7 -foot dome for a short-focus. Schmidt photographic telescope of 24 -inch aperture, and a small transit instrument for the use of students.

The second floor contains thirteen offices for members of the staff and six north rooms for measuring instruments.

On the first floor are the library, a seminar room, and ten offices for members of the staff and research students.

The principal laboratory on the basement floor is cruciform, surrounding the head of the 75 -foot spectrograph. Openings into the tower will admit light to the slit from arc, spark, furnace, and other sources, mounted in convenient positions. Here also will be a magnet for the Zeeman effect, and the large interference spectrograph, upon the slit of which a solar image of any desired diameter can be formed. A tunnel connects this laboratory with the electric power plant. There are five other laboratories on this floor, one of which will contain a vertical concave grating spectrograph of $2 \mathrm{I}$-foot focal length. In addition there are six photographic dark rooms, an instrument shop, a glass-blowing laboratory, a switchboard room, and a long optical testing tunnel.

The sub-basement contains a large laboratory surrounding the tower; several rooms for general research; photographic, photometric, and chemical laboratories; storage battery room; and six photographic dark rooms. At this level, in the annex, are the large machines of the power plant, while the transformers, etc., are also in the annex on the main floor.

The second sub-basement contains storage vaults for astronomical and physical photographs, cabinet files, rooms for stereocomparators, microphotometers, and other special measuring instruments, several general laboratories, supply closet, pump room, and apparatus storage room.

The building of the Astrophysical Laboratory has been completed, and the coelostat telescope, designed and constructed in our shops, has been mounted on the tower. Some of the other equipment is also in place, but the 75 -foot spectrograph is not yet ready, and other apparatus is under construction. 
PLATE XI

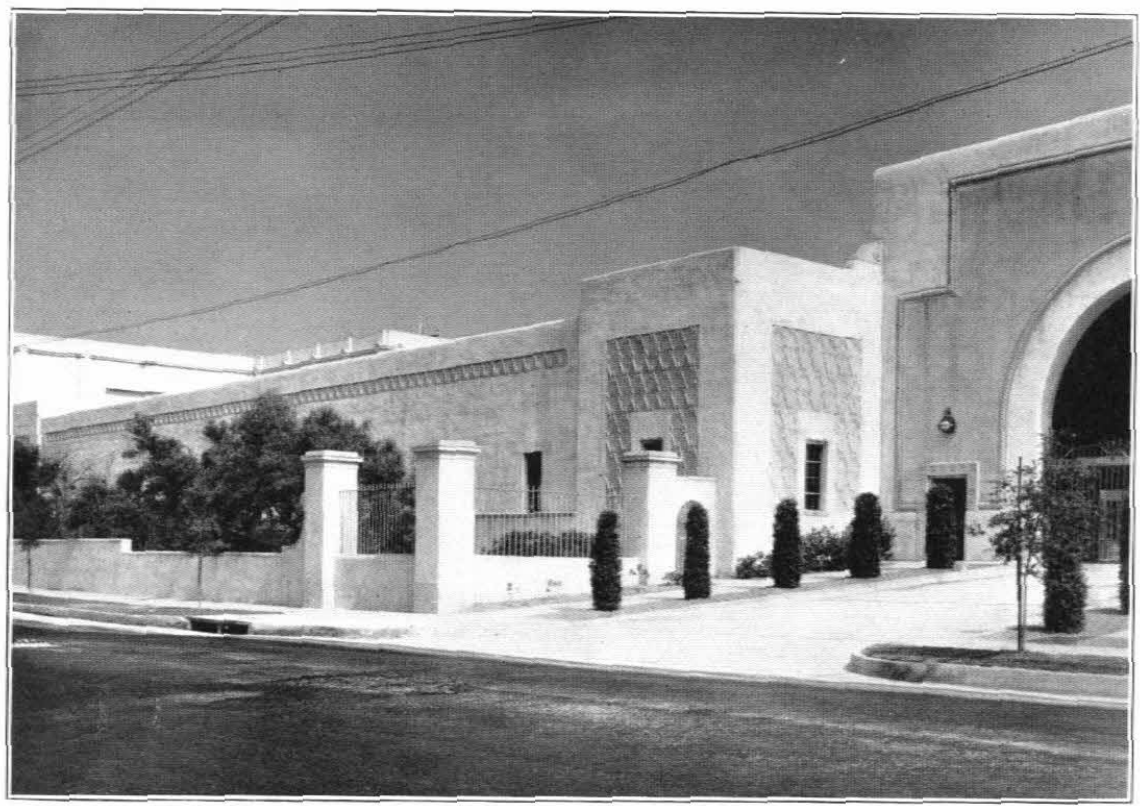

FIG. I.-Instrument Shop

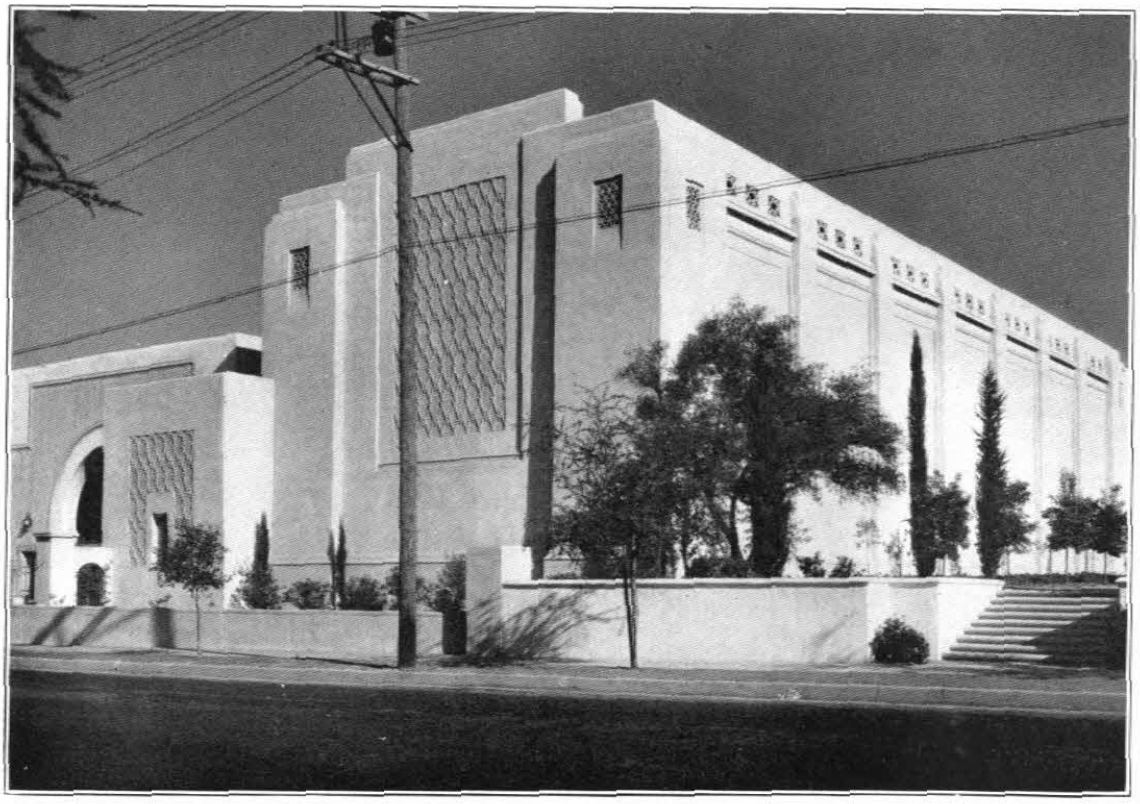

FIG. 2,-Optical Shop 


\section{INSTRUMENT SHOP}

Ever since my first work in spectroscopy fifty years ago I have increasingly realized that a combination of observatory, laboratory, and instrument shop is essential in our chosen field of astrophysical research. Thus while for large and important pieces of routine work, requiring the continued use for many years of the same instruments and methods, an instrument shop may be unnecessary, it is indispensable if rapid advances are to be made in developing the special devices required in the initiation of new methods. The instrument shop of the Mount Wilson Observatory is as busy today as it was when constructed thirty years ago, and future advances will continue to depend upon its operation.

The first requirement of the new Astrophysical Observatory was therefore a suitable instrument shop, with modern machine tools adequate to deal with the problems in view. While these tools need not be large enough to permit the construction of such a huge instrument as the 200-inch telescope mounting, they must be chosen with reference to the scale of its auxiliary apparatus, and also with an eye to the requirements of our optical work. Here again our experience at the Mount Wilson Observatory was called upon as a guide, with results which thus far have proved very satisfactory.

The site of the Instrument Shop was easily determined in the light of the same experience. It should be in close touch with the Astrophysical Laboratory and also with our Optical Shop. At an early stage of this undertaking, when it appeared likely that the 200-inch mirror might have to be cast and figured at its permanent site, the question of shop location seemed less simple. But when it became evident that the best procedure would be to utilize the factories of the General Electric Company or the Corning Glass Works for the manufacture of the large disks, the solution adopted became obvious. A site on the campus of the California Institute also carries with it many other advantages, which need not be enumerated here.

The Instrument Shop, shown in Plate XI, Figure I, is a one-story (and mezzanine) building of reinforced concrete 70 by 197 feet, facing on California Street and adjoining the Optical Shop. It is well lighted, both by windows on the north and south sides and by in- 
clined skylights of the "sawtooth" type, familiar in machine-shop construction. Its broad doorway to the east, opening into the arched entranceway connecting it with the Optical Shop, easily permits the passage of a loaded motor truck or the admission of large grinding tools used for figuring the telescope mirrors. A 5 -ton electric crane runs overhead through the central bay, greatly facilitating the handling of heavy castings. In the southwest corner is the pattern and woodworking shop, 20 by 88 feet, equipped with benches, pattern lathe, 36 -inch band saw, 30 -inch disk and spindle sander, vertical borer, speed lathe, circular saw, two-speed surfacer, and a planer and jointer, all motor-driven, with various attachments and the necessary hand tools.

The central bay, about 20 feet wide, contains some of the larger machine tools, while others occupy the wide area on the south front, east of the pattern shop. North of the central bay are rooms for painting and lacquering, hardening (with furnace), forging and welding, grinders, a shop for small instrument work, offices, tools and supplies, metal stock, and a gear-cutting shop. A partial mezzanine floor contains drafting-rooms, steel storage balcony, etc. The basement, most of which is unexcavated, contains a transformer vault, a switchboard room, locker and storage rooms, and space for the refrigerating machinery required for the Optical Shop.

The machine tools, which are all motor-driven, include one horizontal boring, drilling, and milling machine; one 36 by 36 inch open side planer; one 25 by 50 inch sliding bed gap lathe; one 16 by 60 inch lathe; one I 2 by 24 inch universal and tool grinding machine; two $\mathrm{I} 3$ by 48 inch lathes (one with precision lead-screw); one 28 by Io by I8 inch universal milling machine; one 36 -inch gear hobber for cutting spur, worm, and helical gears; two single-spindle sensitive drill presses; one 20 inch by 16 foot lathe; one 4 -foot radial drill; one 20-inch metal-cutting band saw; one 9-inch precision lathe; one small duplex milling machine; one 20-inch standard shaper; two high-speed metal-cutting machines; two arbor presses; one 9-inch bench lathe; two high-speed grinders; two I4 inch by 6 foot Economy lathes; and one 300-ampere portable welding set, welding and cutting blowpipes, etc.

The superintendent of the Instrument Shop, Mr. G. W. Sher- 
burne, had many years of experience at the Mount Wilson Observatory, both in the construction of instruments and in the erection of the roo-inch telescope.

\section{OPTICAL SHOP}

The task of designing an optical shop in which a 200-inch paraboloidal mirror can be made and accurately tested necessarily involves much experience and study. The building must be large enough to permit Foucault or other tests of extreme delicacy to be applied in connection with a 120 -inch mirror; the air within it must be of great homogeneity and nearly constant in temperature and humidity; and the effects of vibration from any source must be eliminated. An overhead crane capable of carrying very heavy loads must be provided. Moreover, several smaller rooms for work on auxiliary mirrors and grinding and polishing tools are required. These conditions, combined with the fact that the building and all its machinery must remain available for many years to permit of additional optical work and the refiguring of the large mirrors in case of any possible slow changes in form or polish, indicate that no temporary structure will meet the rigorous requirements of the problem.

The Optical Shop shown in Plate XI, Figure 2, recently erected adjoining the Instrument Shop just described, is proving itself to be suitable for our needs. The architectural design, made by Mr. G. W. Iser, embodies the ideas of Messrs. Anderson, Pease, Porter, and other members of our staff, combined with principles of construction due to Professor R. R. Martel and a scheme of heating, cooling, and ventilating worked out by Messrs. Hunter and Hudson. The outside dimensions of the main building, which consists of a single room just large enough for figuring and testing the 200-inch mirror, are 57 by 178 by 50 feet. The interior height of this room, from insulated concrete floor to ceiling lined with 2-inch cork, is 39 feet. Above it is an attic about 8 feet high, fully ventilated by numerous ducts, to protect the ceiling from the heat of the sun on the roof. Adjoining the main building on the west is an annex of two stories and basement, containing the smaller rooms and testing tunnel needed for work on mirrors up to 36 inches in aperture.

The entire building is constructed of concrete, heavily reinforced 
with steel, and the walls are lined with 3 inches of cork. At the south end of the main room is an observation gallery, completely glassed in, from which visitors can see the optical work in progress. A special air-conditioning system, designed to meet our specifications, regulates the temperature and humidity of the air. The overhead electric crane, provided with the fast and slow motions required in handling the large mirrors, runs the entire length of the room. This has been tested with a load of 62 tons, and proves to be well adapted for its purpose.

The grinding machine for the I20-inch mirror was designed and constructed in our shop, and the 200 -inch grinding machine is now being built there. The following machines are used in the smaller rooms of the optical annex, where the lenses for the solar furnace were made and the coelostat mirrors are being figured: a 2-foot grinding and polishing machine; a 4-spindle grinding and polishing machine for small work; a 2-spindle horizontal grinder with 24-inch and 42 -inch plates; a portable edge grinder for disks from 18 to 60 inches aperture; a small edge grinder for lenses and disks up to I4inch aperture; a high-speed portable bench grinder for small lenses; a I 7-inch drill press used as a "biscuit cutter,"; a 3 -foot grinding and polishing machine (loaned by Mount Wilson Observatory); three knife-edge testing outfits; and miscellaneous machine and hand tools. A 6o-inch grinding machine, when needed, can be borrowed from the Mount Wilson Observatory.

Dr. John Strong occupies a laboratory at the north end of the building, where he has developed his process for coating mirrors with aluminum.

Mr. M. H. Brown, with several assistants, is now grinding the I20-inch Pyrex disk, after completing a large number of smaller mirrors and lenses.

\section{AUXILIARY INSTRUMENTS}

The auxiliary instruments for the Astrophysical Observatory and Laboratory are of three classes: (I) those used as attachments or auxiliaries of the 200-inch telescope, (2) those required for the observational and experimental work of the Astrophysical Laboratory, and (3) those needed for the measurement and reduction of astro- 
nomical and physical photographs. Some of the chief instruments of the Laboratory, such as the tower telescope and spectrographs and the solar furnace, have been mentioned above. Six machines for measuring spectra have been built in our shop, and two microphotometers, which are constantly in use, have been purchased. Without dwelling on other apparatus falling under (2) and (3), the concluding section of this paper may be devoted to the attachments of the 200-inch telescope.

It goes without saying that if the efficiency of a large telescope can be doubled or trebled by devising some small and relatively inexpensive attachment, this method of procedure is decidedly preferable to a large and expensive increase in aperture. We have therefore carried on a series of investigations with this end in view.

Ross correcting lens.- The importance of multiplying the photographic range of the 200 -inch reflector in order to permit the study of very faint or remote stars and nebulae led to the adoption of the ratio $\mathrm{f} / 3.3$ for the large mirror. Such a ratio implies a very small field, and one of our first moves was to find a means of obviating this difficulty without changing the ratio of focal length to aperture. Accordingly, Dr. Frank E. Ross, of the Yerkes Observatory, who has had long experience in designing lens systems, was invited to attack the problem of devising a correcting lens of zero power.

Throughout our work on the 200-inch telescope, we have had the advantage of testing all auxiliary apparatus with the telescopes on Mount Wilson. Reciprocally, the Mount Wilson Observatory has had the immediate use of the various new devices developed in the 200-inch telescope project. In this way both the California Institute and the Mount Wilson Observatory have profited greatly. In the present case it was thought wisest to begin the experiment by devising a correcting lens for the 6o-inch Mount Wilson reflector.

The only aberration of outstanding significance in the focal plane of a paraboloidal mirror is coma, which is directly proportional to the radius of the field and the square of the aperture ratio of the mirror. Dr. Ross finds that a series of lenses may be designed for correcting coma, involving a loss of light of about 0.25 mag., slightly more than that produced by the silvered surface of a Newtonian flat. 
The correcting lens made by Fecker for the 60-inch reflector is of 8inch aperture, and is mounted I $_{5}$ inches from the Newtonian focus. It is only approximately of zero power, as it increases the focal length of the mirror by 4.4 inches, or I.4 per cent. This involves a displacement outward of the focal point by 2.7 inches. The enlargement of the field of good definition is very striking, as is shown by a comparison of the star images at a distance of $27^{\prime}$ from the axis of the 6o-inch reflector as photographed with and without the correcting lens. ${ }^{5} \mathrm{~A}$ similar correcting lens was also designed by Ross for the Ioo-inch telescope, and constructed in the Optical Shop of the Mount Wilson Observatory.

As both of these lenses give excellent results, Dr. Ross has designed two separate correcting lenses for the 200-inch telescope. Both of these will remove coma and thus render possible measures of the highest precision in photographic photometry and the determination of star positions. The first will have a spherical aberration confusion disk I". 5 in diameter for use under the best conditions of seeing, when it should increase the area of the field at the principal focus of the 200-inch mirror about tenfold. The second, for use under less perfect conditions, will have a confusion disk of 2 ". 5 , and will increase the area of the useful field from twenty to thirty times. ${ }^{6}$

Rayton lens.-Prior to the initiation of the 200-inch telescope project, a large number of short-focus camera objectives were tried in the spectrograph used with the roo-inch telescope to determine the radial velocities of extra-galactic nebulae. Good results were obtained with some of these lenses, but it was our hope that lenses of still shorter focal length could be designed. Dr. W. B. Rayton, of the Bausch and Lomb Optical Company, was therefore requested to make a special study of the problem.

After the completion of a lens having a speed of $f / 2.4$, which gave good results with the roo-inch telescope, a lens of the type of a 4 -mm microscope objective was designed by Dr. Rayton at the suggestion of Dr. Anderson. This has an equivalent focus of $32 \mathrm{~mm}$ and a rela-

${ }^{5}$ Ross, "Astrometry with Mirrors and Lenses," Ap. J., 77, 243, Pl. VII, I933; Mt. W. Contr., No. 467 .

${ }^{6}$ Ross, "The Optics of Reflecting Telescopes," Pub. A.S.P., 46, 339, I934; "Lens Systems for Correcting Coma of Mirrors," Ap. J., 81, 156, 1935. 
tive aperture of $f / 0.59$. When substituted by Mr. Humason for the fastest lens previously obtainable for the nebular spectrograph of the roo-inch telescope, it was found to show excellent definition and a great gain in speed. ${ }^{7}$ It is with this lens that the extremely high radial velocities of the very remote nebulae have been determined by Mr. Humason, leading to the deduction by Dr. Hubble of the linear relationship between velocity and distance of the extra-galactic nebulae ("the expansion of the universe") .8

B.S.I.R.A. lens.-Subsequently I took up the same problem with Sir Herbert Jackson, then director of the British Scientific Instrument Research Association. At his suggestion Mr. R. J. Bracey, a member of his staff, has successfully calculated an immersion objective of the extraordinary ratio of $f / 0.35$. With the continued cooperation of Dr. Harry Moore, Sir Herbert Jackson's successor, this lens has recently been completed for us by Messrs. R. and J. Beck, Limited, of London. The rest of the optical system of the spectrograph (two prisms and a collimator lens) were made by Messrs. Ross, Limited, and the entire combination has been satisfactorily tested at the laboratory of the Research Association in London. In this unique objective the focus is on the plane surface of the rear lens of the system, with which the plate is kept in optical contact by a special immersion fluid. As the laboratory tests were successful, the optical parts were sent to Pasadena, where the spectrograph to carry them is now under construction in our Instrument Shop. It will soon be tested on nebulae, in combination with the Ioo-inch telescope.

Photo-electric amplifier.-At the beginning of this general study of auxiliary instruments an arrangement was made with Dr. Joel

7 Rayton, "Two High-Speed Camera Objectives for Astronomical Spectrographs," Ap. J., 72, 59, 1930.

${ }^{8}$ See various papers in this Journal by Humason and Hubble. In actual practice, a twelfth (photographic) magnitude star, which formerly required an exposure of about two hours with two prisms, can now be secured in ten minutes. On faint nebulae exposures of twelve hours have been reduced to about one-eighth of this time. The increased slit width, possible because of the shorter focal length of the Rayton lens, is, of course, an important factor. Some valuable experiments have also been made with a single Zeiss lens very kindly loaned by Lord Rayleigh. It was formerly used by him in photographing the spectrum of the aurora. 
Stebbins to push his development of the photo-electric cell to the farthest attainable limits. His long experience with cells best suited for astrophysical investigations was a great advantage, but at first he was unable to improve materially the excellent equipment he was already using. Dr. Albert E. Whitford, an advanced student working in the University of Wisconsin in co-operation with Dr. Stebbins, subsequently succeeded in constructing a photo-electric cell, mounted in vacuo with a special amplifier, with which Dr. Stebbins has secured remarkable results on Mount Wilson. By actual test, without a telescope, this amplifier easily shows a candle 7 miles away-farther than it can be seen by the eye. This in spite of the absorption of the intervening air. With the roo-inch reflector the limit of detection of a candle would be 3,000 miles, assuming no absorption in the atmosphere beyond the first mile.

As an illustration of Dr. Stebbins' recent work, which was done with the assistance of Dr. Whitford, reference may be made to a paper on the diameter of the Andromeda Nebula, showing its length and breadth to be at least double that previously known. ${ }^{9}$ Dr. Stebbins has applied this photo-electric amplifier to many other important uses, which show how greatly it will increase the efficiency of the 200-inch telescope. This advance is especially striking to the writer, who used an Elster and Geitel photo-electric cell in spectroscopic work at the University of Berlin in the winter of $1893^{-1894}$, in association with Dr. H. M. Goodwin.

Dr. Sinclair Smith, a member of the Mount Wilson Observatory staff who has devoted part of his time to the 200-inch project, has made extensive studies of various auxiliary instruments and methods, including the photo-electric cell and the radiometer. A paper assigning a lower limit to the useful sensitivity of the photo-electric cell should be mentioned in the present connection. ${ }^{\mathrm{Io}}$

After the completion of the designs of the 200-inch telescope

9 Stebbins and Whitford, "The Diameter of the Andromeda Nebula," Mt. Wilson Comm., No. I1 3 ; Proc. N.A.S., 20, 93, 1934. An important application of this amplifier is described in Stebbins' article on "The Dark Galaxy" in the Pop. Sc. Mo. for August, I934.

${ }^{10}$ Smith, "The Limiting Magnitude Observable with a Photo-electric Stellar Photometer," Ap. J., 76, 286, 1932; Mt. Wilson Contr., No. 457. 
mounting and the Observatory buildings, they will be described and illustrated in this Journal.

I cannot close this paper without reference to the invaluable aid received from the officers of the General Education Board and the Rockefeller Foundation. They are most generous in giving their time and thought to technical problems, both financial and scientific, whenever they are brought before them. In connection with the 200-inch mirror disk and the design of the telescope mounting, President Mason's long experience as a physicist has been of great value. As a trustee of the California Institute and a member of the Mount Wilson Observatory of the Carnegie Institution of Washington, I gratefully appreciate that the cordial co-operation of all of these institutions made this project possible.

Pasadena, California

March 1935 